\title{
Respon Mahasiswa Komunikasi Penyiaran Islam Angkatan 2014 terhadap Dakwah Ustad Evie Effendi
}

\author{
Nida Aidah $^{1 *}$, Tjetjep Fachruddin ${ }^{1}$, Encep Taufik Rahman ${ }^{1}$ \\ ${ }^{1}$ Jurusan Komunikasi dan Penyiaran Islam. UIN Sunan Gunung Djati Bandung
}

*Email : nidaaidab0@gmail.com

\begin{abstract}
ABSTRAK
Dakwah merupakan usaha mengubah situasi kepada situasi yang lebih baik dan sempurna, baik terhadap pribadi maupun masyarakat. Perwujudan dakwah bukan sekedar usaha peningkatan pemahaman keagamaan dalam tingkah laku dan pandangan hidup saja, tetapi juga lebih menyeluruh dalam berbagai aspek. Oleh karena itu seorang da'i dituntut harus mampu membangkitkan minat mad'u agar mau mengikuti setiap kegiatan dakwahya. Sebagaimana dakwah yang dilakukan ustad Evie effendi yang berhasil membangkitkan minat khususnya kalangan muda terhadap dakwah ustad Evie Effendi. Keunikan dakwah ustad Evie Effendi terletak pada metode, pesan dakwah dan cara penyampainnya yang mudah difahami. Tujuan penelitian ini yaitu untuk mengetahui perhatian, pemahaman dan penerimaan Mahasiswa Komunikasi Penyiaran IslamUniversitas Islam Negeri Sunan Gunung Djati Bandung Angkatan 2014 Terhadap Dakwah Ustad Evie Effendi. Teori yang digunakan dalam penelitian ini adalah teori SOR (Stimulus, Oraganism, dan Respons) diambil dari teori sosiologi komunikasi yang dikemukakan oleh Onong Uchjana Effendi dalam buku "Ilmu, Teori dan Filsafat Komunikasi” (2003) yang bertujuan untuk mengetahui stimulus (materi pesan) yang disampaikan komunikan (Da’) ditolak atau diterima. Komunikasi akan berlangsung jika ada perhatian dari komunikan lalu komunikan mengerti, menerima dan terjadilah proses mengubah sikap. Metode penelitian yang digunakan adalah metode deskriptif bertujuan untuk menjelaskan, meringkaskan, meringankan berbagai kondisi, berbagai situasi atau berbagai variable yang timbul dimasyrakat yang menjadi objek penelitian. Jenis data yang digunakan yaitu data kuantitaf yang dapat menghasilkan data yang akurat setelah melakukan perhitungan angka yang tepat. Hasil dari penelitian ini, perhatian mahasiswa terhadap dakwan ustad Evie Effendi mendapatkan respon yang baik dengan demikian mahasiswa selalu memperhatikan kegiatan dakwah Ustad Evie Effendi Pemahaman mahasiswa terhadap dakwah Ustad Evie Effendi dimulai dari segi materi dakwah dan pemahaman keagamaan yang
\end{abstract} 18 Diterima: Januari 2019. Disetujui: Februari 2019. Dipublikasikan: Maret 2019 
meningkat mendapatkan respon yang positif. Penerimaan mahasiswa terhadap dakwah Ustad Evie Effendi dari segi materi dakwah, mengamalkan apa yang telah disampaika oleh Ustad Evie Effendi.

Kata Kunci : Dakwah, Respon, Evie Effendi

\section{ABSTRACT}

$D a^{\prime} w a h$ is an effort to change the situation to a better and perfect situation, both for individuals and society. The embodiment of da'wah is not just an effort to increase religious understanding in behavior and outlook on life, but also more thoroughly in various aspects. Therefore a da'i is required to be able to arouse interest in mad'u so that he wants to participate in each of his preaching activities. As preaching carried out by Ustadz Evie Effendi who succeeded in arousing interest, especially among young people, towards the da'wah of ustad Evie Effendi. The uniqueness of Ustadz. Evie Effendi's da'wah lies in the methods, da'wah messages and ways of conveying that are easily understood. The purpose of this study is to find out the attention, understanding and acceptance of Islamic Broadcasting Communication Students of the State Islamic University of Sunan Gunung Djati Bandung in 2014 against Da'wah Ustadh Evie Effendi. The theory used in this study is the SOR theory (Stimulus, Oraganism, and Response) taken from the sociological theory of communication proposed by Onong Uchjana Effendi in the book "Communication Science, Theory and Philosophy" (2003) which aims to find out the stimulus (message material) delivered by the communicant (Da'i) rejected or accepted. Communication will take place if there is attention from the communicant then the communicant understands, accepts and there is a process of changing attitudes. The research method used is descriptive method aimed at explaining, summarizing, alleviating various conditions, various situations or various variables that arise in the community that are the object of research. The type of data used is quantitative data that can produce accurate data after calculating the right number. The results of this study, the attention of students to cleric ustad Evie Effendi received a good response so students always pay attention to Ustadh Evie Effendi's preaching activities. Students' understanding of Ustadz. Evie Effendi's preaching began in terms of the material of da'wah and increased religious understanding received a positive response. Student acceptance of the preaching of Ustadz Evie Effendi in terms of the material of da'wah, practicing what was received by Ustadh Evie Effendi.

Keywords : Da'wah, Response, Evie Effendi

\section{PENDAHULUAN}

Dakwah merupakan usaha mengubah situasi kepada situasi yang lebih baik dan sempurna, baik terhadap pribadi maupun masyarakat. Perwujudan tingkah laku dan pandangan hidup saja, tetapi juga lebih menyeluruh dalam berbagai aspek. 
Wahidin Saputra (2012: 61) mengemukakan bahwa secara prinsip tujuan dakwah adalah tujuan yang hendak dicapai oleh kegiatan dakwah. Adapun tujuan dakwah dibagi menjadi dua yaitu tujuan jangka pendek dan tujuan jangka panjang. Tujuan jangka pendek yang dimaksud adalah agar manusia mematuhi ajaran Allah dan Rasul-Nya dalam kehidupan sehari-hari, sehingga terciptanya manusia yang berakhlak mulia, dan tercapainya individu yang baik.

Dengan demikian, dakwah merupakan satu bagian yang pasti ada dalam kehidupan umat beragama. Dalam ajaran islam dakwah merupakan suatu kewajiban yang di bebankan oleh agama. Proses dakwah bisa dilakukan dengan berbagai cara, yang salah satunya dengan ceramah. Ceramah merupakan salah satu aktivitas dakwah yang sudah lazim dilaksanakan. Di Indonesia ceramah dilakukan di tempat-tempat seperti musholla dan masjid.

Ceramah merupaka salah satu metode dakwah yang sangat penting dalam meningkatkan kuantitas umat dan merupakan media alternatif untuk mengajak umatnya dalam meningkatkan hubungan antara umat muslim dengan penciptanya (Hablun Min Allah) dan hubungan antara umat muslim dengan sesamanya (Hablun Min An-Naas), juga ceramah merupakan jalan utama bagi persiapan untuk memajukan umat (Ma'ruf, 1981:16).

Manfaat ceramah akan terasa bermakna bagi pendengarnya, apabila kebutuhan masing-masing terpenuhi. Para $d a^{\prime} i$ sangat penting untuk mengetahui kebutuhan-kebutuhan mereka, agar ia dapat menyesuaikan atau mengarahkan jamaahnya pada tujuan yang ingin dicapainya.

Dalam kegiatan dakwah seorang da'i merupakan bagian dari proses interaksi para pemikir yang saling bekerja sama, saling mendengarkan materi dakwah dalam pengertian dan apresiasi wahyu-wahyu ilahi. (Wahidin, 2012: 61).

Namun kegiatan dakwah yang dilakukan sering kali terdengar monoton, hal tersebut dikarenakan kegiatan dakwah yang disampaikan dengan gaya bicara atau metode yang monoton pula. Maka dari itu seorang pelaku dakwah (da' $)$ perlu mengaplikasikan retorika dalam kegiatan dakwahnya. Adanya karakteristik gaya dan bahasa yang menarik, kegiatan dakwah yang dilakukan pun tidak lah monoton. Tentunya gaya bicara atau bahasa disesuaikan dengan mad'u yang akan dihadapi. Disinilah seorang da'i dituntut untuk berlaku arif atau bijaksana dalam berdakwah. (Nisa, 2018:3).

Seorang Da'i dituntut untuk mampu membangkitkan minat jamaahnya, agar mau mengikuti setiap kegiatan dakwahnya, karena dari dakwah tersebut Islam dapat tersampaikan secara menyeluruh dan berkesimbungan. Sebagai tokoh dalam masyarakat seorang da'i dituntut untuk mempu merangsang dan mendorong serta mengajak kepada mad'u untuk senantiasa mengikuti kegiatan dakwahnya, guna mendapatkan petunjuk dan hidayah dalam kehidupannya.

Sehingga yang dimaksud dengan pesan dakwah tidak harus selalu memuat kata "dakwah", tidak pula harus selalu ada ayat atau hadist yang dikutipnya. 
Selama ia berkomunikasi dengan mengandung ajakan atau pelaksanaan untuk bertambah iman dan taqwa kepada Allah, menampakan kebenaran, keadilan, kemaslahatan, dan seterusnya dalam kehidupan sehari-hari yang merupakan implementasi dari tauhid, maka ia termasuk pesan dakwah. (Kusnawan, 2004: 4).

Dalam berdakwah pesan-pesan dakwah dituangkan dalam bentuk lisan. Hal inilah yang dilakukan oleh seorang aktivis dakwah, dalam menyiarkan dakwahnya di setiap ceramahnya.

Dalam hal ini kegiatan dakwah yang dilakukan oleh seorang aktvis dakwah yaitu ustad Evie Effendi merupakan bentuk usaha dalam menarik perhatian jamaahnya dimana beliau berdakwah berhasil membangkitkan minat khususnya dikalangan muda, keunikan dakwah ustad Evie Effendi terletak pada metode dakwahnya, pesan dan materi dakwah dan cara penyampaianya yang mudah difahami. Sehingga isi pesan dakwah tidak sekedar apa yang diketahui dan disajikan. Meliankan Isi pesan dakwah adalah kebenaran yang diterima secara tulus dan pembenarannya yang didasarkan pada pertimbangan-pertimbangan atas beberapa alternatif.

Ustad Evie Effendi adalah seorang da'i kondang yang berasal dari Bandung. Beliau telah mempunyai banyak jam terbang ceramah di berbagai statius televisis swasta sertadiberbagai daerah baik itu didalam kota atau diluar kota. Beliau mempunyai banyak majelis ta'lim yang salah satunya berada di daerah Panyawangan Kabupaten Bandung. Dalam setiap kegiatan dakwah Ustad Evie Effendi jamaah yang hadir selalu banyak dan penuh oleh kebanyakan kalangan muda mudi namun respon jamaah terhadap pelaksanaan dakwah ustad Evie Effendi tidak selalu positif.

Dengan melalui dakwah ustad Evie Effendi yang merupakan seorang tokoh dakwah terkenalyang selalu mengajak kepada segenap masyarakat khususnya kalangan muda untuk mengikuti perintah Allah dan menghidari larangan-Nya. Jamaah kalangan muda yang hadir lebih tertarik datang karena ustad Evie Effendi merupakan tokoh dakwah yang sudah terkenal bukan karena memang menyukai kegiatan dakwah.

\section{LANDASAN TEORITIS}

Teori S-O-R sebagai singkatan dari Stimulus - Organism - Response. Teori ini berasal dari psikologi yang kemudian menjadi teori komunikasi, karena objek materi dari psikolog dan komunikasi sama yaitu manusia yang komponennya meliputi sikap, opini dan prilaku. Menurut teori S-O-R, efek yang ditimbulkan adalah reaksi khusus, seingga sesorang dapat mengharapkan dan memeperkirakan kesesuaian antara pesan dan reaksi komunikasi. Adapun unsurunsur dalam teori ini adalah: Pesan (Stimulus, S), Komunikan (Organism, O), Efek (Respons, R). Dalam proses perubahan komunikasi berkenaan dengan perubahan 
N. Aidah, T. Fahruddin, E.T.Rahman.

sikap adalah aspek "bow" bukan "what" dan "why". Jelasnya how to communicate, dalam hal ini how to change the attitude, bagaimana mengubah sikap komunikan.

Mar'at dalam bukunya "Sikap manusia, perubahan serta pengukurannya, mengutip pendapat Hovland, Jeans da Kelley yang menyatakan bahwa dalam menelaah sikap yang baru, ada tiga variable penting yaitu : Perhatian, Pengertian, Penerimaan (Onong, 1993). Dalam buku Abu Ahmadi perhatian berhubungan erat dengan kesadaran jiwa terhadap suatu objek yang reaksinya pada suatu waktu. Objek yang menjadi sasaran mungkin hal hal yang ada dalam dirinya, sehingga perhatian dapat di definisikan sebagai keaktifan jiwa yang di arahkan kepada sesuatu objek, baik di dalam maupun di luar dirinya.(Ahmadi, 2003: 9697). Dalam buku Abu Ahmadi di sebutkan bahwa "Pengertian" adalah hasil pikir seseorang yang merupakan ringkasan sifat-sifat pokok dalam bentuk perkataan. (Ahmadi, 2003: 110). Sedangkan "Penerimaan" dapat di artikan sebagai hasil keputusan mengenai suatu perubahan sikap agar sesuai dengan sikap yang diharapkan. (Mar'at, 1982: 31).

\section{Stimulus}

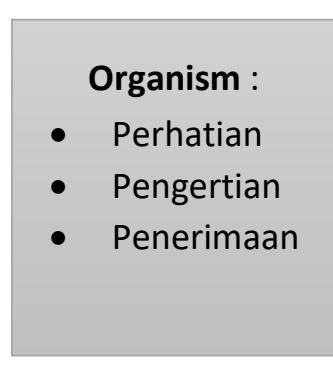

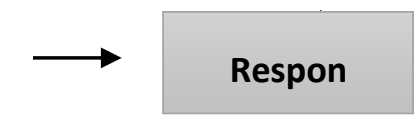

Gambar diatas menunjukan bahwa respon dipengaruhi oleh beberapa unsurnya yaitu stimulus dan organism (proses yang terjadi pada individu). Maka dari itu, sebuah respon dalam kegiatan dakwah juga bisa dilihat dari skema diatas, atau sebagai berikut:

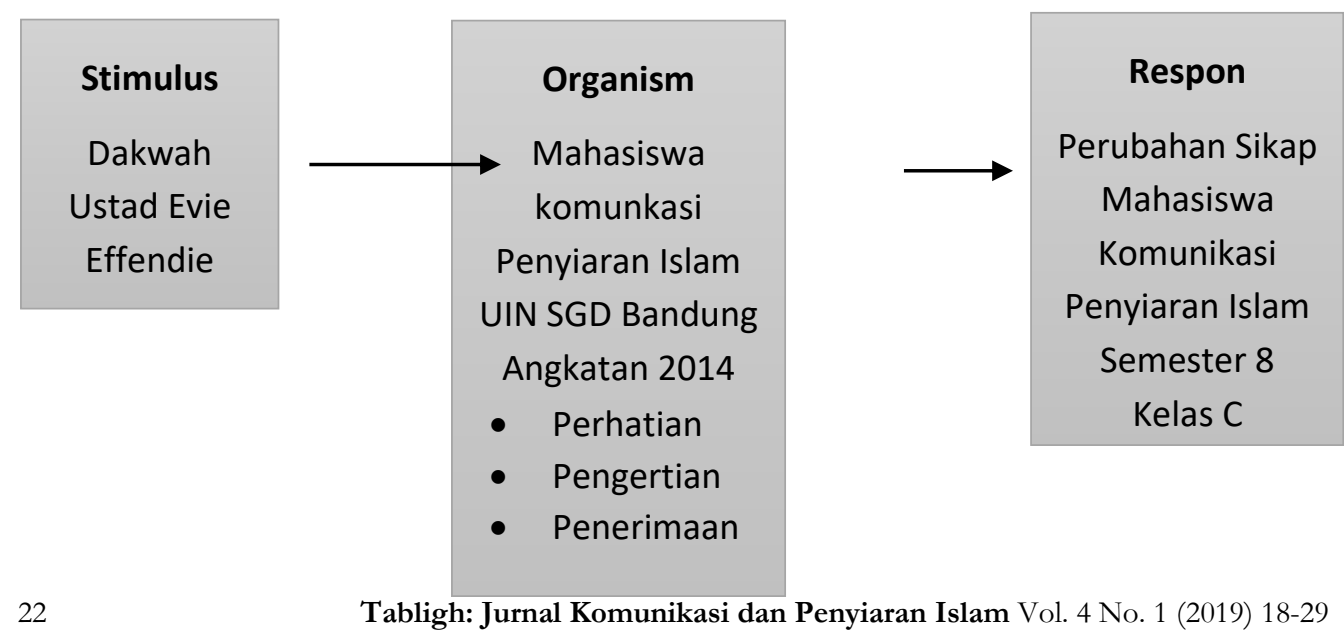




\section{Kerangka Konseptual}

Dakwah Menurut Ilyas Islmail dalam bahasa al-Qur'an, dakwah terambil dari kata da'wah yang secara etimologi memiliki kesamaan makna dengan al nida yang berarti menyeru dan memanggil. Adapun dari tinjauan aspek terminologis, pakar dakwah syekh Ali Mahfuz mengertikan dakwah dengan menagajak manusia kepada kebaikan dan petunjuk allah, dengan menyeru kepada kebiasaan yang baik dan melarang dari kebiasaan buruk supaya mendapatkan keberuntungan dunia dan akhirat. (Ismail \& Prio, 2011: 28).

Dari definisi di atas dapat disimpulkan bahwa dakwah adalah sebuah kegiatan usaha mengajak, menyeru dan memanggil manusia untuk berbuat pada kebaikan dan menjauhi segala larangannya dengan melakukan segala perintah Allah dan Rasul-Nya untuk mendapatkan ridhka dan keselamatan dunia dan Akhirat.

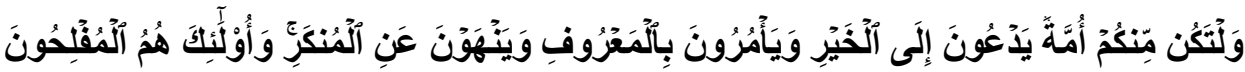

"Dan hendaklah ada dia antara kamu segolongan umat yang menyeru kepada kebajikan dan menurub pada yang Ma'ruf dan mencegah dari yang mungkear merekalah orang-orang yang beruntung." (Departemen Agama RI, 2010).

Ayat di atas menjelaskan bahwa dakwah adalah kewajiban pada setiap umat muslim untuk mengajak pada jalan kebaikan yang di ridhoi Allah.

\section{Bi al-lisan}

Dakwah bi al-lisan merupakan dakwah yang dilaksanakan melalui lisan, yang dilakukan antara lain dengan ceramah-ceramah, khutbah, diskusi, nasihat, dan lain-lain. Metode ceramah ini tampaknya sudah sering dilakukan oleh para juru dakwah, baik ceramah di majlis taklim, khutbah jum'at atau cermah pengajian-pengajian (Munir, 2009: 11).

Metode dakwah bi al-lisan ini sudah ada sejak zaman rasulullah saat menyebarkan ajaran islam nya yang secara diam-diam saat di madinah, beliau menggunakan cara ini untuk mengajak kepada rakyatnya yang belum beragama islam dengan cara memberikan ajaran-ajaran islam tetapi scara sembunyisembunyi.

Dakwah dikatakan efektif apabila ada respon dari mad'u yang berupa perubahan persepi dalam hal perubahan sikap dan perilaku. Menurut Moekijat komunikasi yang efektif mengandung pengiriman dan penerimaan informasi yang paling cermat, pengertian pesan yang mendalam oleh kedua belah pihak dan pengambilan tindakan yang paling tepat terhadap penyesuaian pertukaran informasi (Moekijat, 1993: 145).

\section{Respon}


N. Aidah, T. Fahruddin, E.T.Rahman.

Menurut Fisher yang dikutip dalam buku Jalaludin Rahmat, "Dalam komunikasi, umpan balik dapat diartikan sebagai respon peneguban, dan servomekanisme internal". Sebagai respon, umpan balik adalah sikap atau prilaku seorang komunikan dalam proses komunikasi. Keberhasilan komunikator dalam menyampaikan pesan, dilihat dari umpan balik komunikasinya. Terlihat dari cara komunikan dalam menangkap pesan dari yang disampaikan oleh komunikator. Umpan balik (feed back) biasanya menandakan proses berjalan lancarnya komunikasi (Rakhmat, 2004: 191).

\section{Mahasiswa}

Dalam Kamus Besar Bahasa Indonesi (KBBI), mahasiswa di definisikan sebagai orang yang belajar di sebuah perguruan tinggi (KBBI, 2018).

Mahasiswa adalah seseorang yang sedang dalam proses menimba ilmu ataupun belajar dan terdaftar sedang menjalani pendidikan pada salah satu perguruan tingggi yang terdiri dari akademik. Mahasiswa dinilai memiliki tingkat intelektualitas yang tinggi, kecerdasan dalam berfikir dan kerencanaan dalam bertindak. Berfikir kritis dan bertindak dengan cepat dan tepat cenderung merupakan sifat setiap mahasiswa.

\section{Kerangka Operasional}

Variabel yang digunakan dalam penelitian ini yaitu variabel bebas atau independen yang merupakan respon mahasiswa UIN Sunan Gunung Djati Bnadung angkatan 2014 (x), dan variabel tidak bebas atau dependen yaitu dakwah Evie Effendie (y).

\begin{tabular}{|c|c|c|c|}
\hline \multicolumn{2}{|r|}{ Variabel } & Sub Variabel & \multirow[b]{2}{*}{\begin{tabular}{l}
\multicolumn{1}{c}{ Indikator } \\
- \\
megiatan dakwah \\
merupakan kegiatan \\
yang positif \\
- Metode yang \\
digunakan menarik \\
- Metode yang digunakan \\
- mudah di terima \\
Pemateri atau da'i \\
menarik perhatian \\
Minat dan tujuan \\
mendengarkan dakwah
\end{tabular}} \\
\hline 1. & $\begin{array}{l}\text { Variabel (x) (Respon } \\
\text { mahasiswa } \\
\text { Komunikasi } \\
\text { Penyiaran Islam UIN } \\
\text { SGD Bandung } \\
\text { Angkatan 2014) }\end{array}$ & a. Perhatian & \\
\hline & & b. Pengertian & 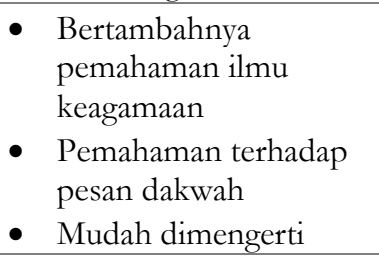 \\
\hline & & c. Penerimaan & 1. Efek Kognitif \\
\hline
\end{tabular}




\begin{tabular}{|c|c|c|}
\hline & & $\begin{array}{l}\text { - Pengetahuan } \\
\text { - Menambah } \\
\text { 2. Efek Afektif } \\
\text { - Kecenderungan } \\
\text { - Perasaan } \\
\text { 3. Efek Konatif } \\
\text { - Sikap } \\
\text { - Prilaku }\end{array}$ \\
\hline \multirow[t]{3}{*}{$\begin{array}{l}\text { 2. Variabel (y) (dakwah } \\
\text { Evie Effendie) }\end{array}$} & a. Evie Effendi & $\begin{array}{lr}\text { Kepiawaian } & \text { Evie } \\
\text { Effendie } & \text { dalam } \\
\text { menyampaikan materi } \\
\text { atau pesan dakwah }\end{array}$ \\
\hline & b. Pesan Dakwah & Materi Mengenai Tauhid \\
\hline & c. Pengemasan & $\begin{array}{l}\text { Metode penyampaian } \\
\text { materi sesuai dengan } \\
\text { ajaran islam dengan } \\
\text { pedoman al-Qur'an dan } \\
\text { Hadist. Dikemas dengan } \\
\text { menarik, juga } \\
\text { memebahas topik islami } \\
\text { menarik yang sedang } \\
\text { hangat dibincangkan }\end{array}$ \\
\hline
\end{tabular}

\section{HASIL DAN PEMBAHASAN}

Berdasarkan hasil yang telah didapatkan dari penelitian yang telah dilakukan pada dimensi perhatian diperoleh skor nilai $\overline{\mathbf{x}}=2,77$, pada dimensi pengertian di Xporoleh skor nilai $\overline{\mathbf{x}}=2,62$, dan pada dimensi penerimaan diperoleh skor nilai $\overline{\mathbf{x}}=2,53$. Skor dari ketiga dimensi tersebut menunjukan bahwa respon mahasiswa Komunikasi Penyiaran Islam Universitas Islam Negeri Sunan Gunung Djati Bandung angkatan 2014 terhadap dakwah ustad Evie Effendi berada pada tingkatan yang berbeda-beda.

Pada dimensi perhatian, mahasiswa Komunikasi Penyiaran Islam Universitas Islam Negeri Sunan Gunung Djati Bandung angkatan 2014 memiliki tingkatan tingkat yang tinggi terhadap dakwah ustad Evie Effendi. Ini dipengaruhi oleh beberapa faktor diantaranya yaitu kegiatan dakwah ustad Evie Effendi merupakan kegiatan yang positif dan bermanfaat, metode dakwah yang 
digunakannya pun menarik dikalangan mahasiswa, mahasiswa menyukai gaya busana ustad Evie Effendi yang memiliki ciri khas yaitu dengan memakai kupluk, jaket kulit dan juga pakai-pakai yang bukan pakaian muslim, dan penggunaan bahasa yang menarik mampu membuat mahasiswa menyukai dakwah ustad Evie Effendi.

Pada dimensi pengertian, mahasiswa Komunikasi Penyiaran Islam Universitas Islam Negeri Sunan Gunung Djati Bandung angkatan 2014 memiliki tingkat yang tinggi terhadap dakwah ustad Evie Effendi. Ini dipengaruhi oleh beberapa faktor diantaranya yaitu: materi dakwah yang dapat mengingatkannya kepada Allah SW'T meskipun terkadang dalam penyampaian pesan dakwah ustad Evie Effendi selalu membuat hal-hal yang lucu, penyampaian pesan dakwah secara jelas walaupun terkadang menggunakan bahasa sunda yang dapat membuat sebagian mahasiswa tidak paham dengan maknanya, pembahasan materi yang sesuai dengan keilmuan mahasiswa, dan mengerti makna sesungguhnya mengenai syariat islam setelah mendengarkan dan melihat dakwah ustad Evie Effendi.

Pada dimensi penerimaan, mahasiswa Komunikasi Penyiaran Islam Universitas Islam Negeri Sunan Gunung Djati Bandung angkatan 2014 memiliki tingkatan tingkat sedang terhadap dakwah ustad Evie Effendi. Ini disebabkan oleh beberapa faktor yaitu: tidak banyak mahasiswa yang menerima materi yang belum difahami dan ketahui sebelumnya, tidak banyak mahasiswa yang dapat mempengaruhi sikap dan prilaku mahasiswa setelah mendengarkan dakwah ustad Evie Effendi, pesan dakwah yang disampaikan sesuai dengan harapan mahasiswa, dan bertambahnya keilmuwan mahasiswa tentang islam setelah mendengarkan dakwah ustad Evie Effendi. Dengan beberapa faktor menarik tersebut mahasiswa menerima dakwah ustad Evie Effendi setelah mendegarkan dan melihat dakwah tersebut.

Berdasarkan dari hasil yang telah didapatkan pada penelitian ini, maka respon mahasiswa terhadap dakwah ustad Evie Effendi ini memberikan efek kognitif, efek afektif dan efek konatif.

Efek kognitif ini berkaitan dengan pikiran, nalar atau rasio. Misalnya komunikasi menyebabkan orang yang semula tidak tahu menjadi tahu, yang semula tidak mengerti menjadi mengerti atau yang semula tidak sadar menjadi sadar. Akibat yang timbul pada diri komunikan yang sifatnya informatif bagi dirinya. Berdasarkan hasil wawancara mahasiswa dan hasil data yang diperoleh dari penyebaran angket bahwa mahasiswa Komunikasi Penyiaran Islam Universitas Islam Negri Sunan Gunung Djati Bandung angkatan 2014 mendapat pengetahuan dan menambah wawasan terhadap keunikan dakwah ustad Evie Effendi, bahwa sejatinya seorang ustad juga bisa melakukan inovasi terhadap isi pesan dan materi dakwahnya.

Efek afektif yaitu efek yang berhubungan dengan perasaan. Misalnya 
komunikasi menyebabkan orang yang semula tidak senang menjadi senang, yang semula sedih menjadi gembira, atau yang semula merasa takut atau malu menjadi berani, yang semula tidak terlau suka menjadi suka dan yang semula merasa tidak tertarik lama-lama berubah menjadi tertarik. Khalayak diharapkan dapat turut merasakan sedih, iba senang dan lain sebagainya setelah mendapatkan pesan dari media masa. Berdasarkan hasil data yang diperoleh bahwa mahasiswa Komunikasi Penyiaran Islam Universitas Islam Negeri Sunan Gunung Djati Bandung angkatan 2014 menyukai dakwah ustad Evie Effendi sedang menyampaikan pesan yang diselipkan dengan hal-hal yang lucu.

Efek konatif yaitu efek yang menimbulkan niatan untuk berprilaku tertentu, dalam arti kata melakukan suatu tindakan atau kegiatan yang besifat fisik atau jasmaniah. Misalnya, komunikasi menyebabkan mahasiswa yang semula mala untuk belajar menjadi rajin, atau orang yang semula perokok menjadi tidak merokok. Berdasarkan hasil data yang diperoleh bahwa mahasiswa Komunikasi Penyiaran Islam Universitas Islam Negeri Sunan Gunung Djati Bandung angkatan 2014 menerima dan mengikuti dakwah ustad Evie Effendi.

\section{PENUTUP}

Berdasarkan pengolahan dan hasil analisis data terhadap respon mahasiswa Komunkasi Islam Penyiaran Angkatan 2014 terhadap dakwah ustad Evie Effendi, diperoleh kesimpulan.

Satu, Perhatian mahasiswa KPI UIN SGD Bandung terhadap dakwah ustad Evie Effendi memiliki nilai $\overline{\mathrm{X}}=2,77$. Sehingga dapat kita ketahui bahwa mahasiswa KPI UIN SGD Bandung memiliki respon positif atau memiliki perhatian yang besar terhadap dakwah ustad Evie Effendi. Hal ini terbukti dari pengolahan angket yang menunjukan bahwa sebagian besar jumlah mahasiswa KPI UIN SGD Bandung menyukai dakwah ustad Evie Effendi yang terkesan berbeda dari yang lainya, dalam segi busana, penyampaian materi dakwah, gaya bahasa yang unik memperlihatkan seorang da'i yang santai namun ceramahnya di dengar dan disimak oleh jamaah.

Dua, Pemahaman mahasiswa terhadap dakwah ustad Evie Effendi memiliki nilai $\overline{\mathrm{X}}=2,62$. Sehingga dapat diketahui bahwa mahasiswa KPI UIN SGD Bandung sangat memahami dakwah ustad Evie Effendi karena dalam berdakwah dikategorikan sangat baik atau positif. Hal ini terbukti dari pengolahan angket yang menunjukan bahwa sebagian besar mahasiswa paham bahwa materi yang disampaikan saat berdakwah lebih mengingatkan kepada Allah SWT, pesan dakwah mengenai keislaman lebih pada untuk memperbaiki akhlak dan perilaku diri. Seorang dai juga perlu melakukan inovasi atau perubahan sedikit dalam menyampaikan pesan dakwah sehingga mahasiswa atau jamaah yang melihat tidak monoton dengan paradigma bahwa ustad hanya 
menyampaikan pesan dakwah saja.

Tiga, Penerimaan mahasiswa terhadap dakwah ustad Evie Effendi memiliki nilai $\overline{\mathrm{x}}=2,53$. Sehingga dapat diketahui bahwa penerimaan mahasiswa terhadap dakwah ustad Evie Effendi dikategorikan positif dan baik. Hal ini terbukti dari pengolahan angket yang menunjukan bahwa sebagian besar mahasiswa KPI menyatakan menerima pesan dakwah ustad Evie Effendi. Tidak banyak mahasiswa yang terpengaruh sikap dan prilakunya setelah mendengar isi pesan dakwah ustad Evie Effendi, sebagian besar mahasiswa sudah mengetahui isi pesan dakwah ustad Evie Effendi dan bertambahnya keilmuwan mahasiswa tentang islam setelah mendengar dan melihat dakwah ustad Evie Effendi.

Mengacu pada temuan-temuan penelitian dilapangan dan kesimpulan yang dikemukakan, maka peneliti memberikan saran kepada pihak-pihak terkait. Satu, untuk mahasiswa KPI UIN SGD Bandung hendaklah sering mengikuti kajian dakwah ustad Evie Effendi secara konsisten dan rajin dengan penuh semangat dan niat ikhlas menuntut ilmu yang diridhoi oleh Allah SWT. Sehingga bisa merubah diri menjadi pribadi yang lebih baik lagi. Serta menjadikan pribadi yang tidak memandang seseorang hanya dari luar saja atau penampilan saja tapi mengetahui kepribadian dan apa yang disampaikannya. Dua, untuk semua umat islam manfaatkanlah waktu kosong dan senggangnya untuk diisi dengan hal-hal yang lebih positif seperti mengikuti kajian dakwah, mendengarkan dan melihat dakwah ustad Evie Effendi bisa di berbagai media sosial tanpa harus keluar. Supaya lebih banyak orang yang bisa menerima pesan dakwah yang disampaikan. Tiga, untuk penelitian berikutnya diharapkan supaya dapat meneliti lebih dalam lagi mengenai pesan dakwah baik itu melalui media mimbar atau media sosial. Karena kini media sosial lebih mudah dan praktis untuk diakses dikalangan masyarakat bahkan hampir untuk semua kalangan sehingga dapat dijadkan sumber referensi untuk kedepannya.

\section{DAFTAR PUSTAKA}

Ahmadi, A., 2003. Psikologi Umum. Jakarta: PT. Rineka Cipta.

Ahmadi, A., 2009.. Psikologi Umum. Jakarta: Rieka Cipta.

Aripudin, A. \& Sukriyadi Sambas, 2007. Dakwah Damai. 2012: Rosdakarya

AS, E. \& Hajir Tajiri, 2009. Etika Dakwah. Bandung: Widya Padjajaran.

Cangara, H., 2014. Perencanaan \& strategi Komunikasi. Depok:: PT. Raja

Grafindo Persada.

DepartemenAgamaRI, 2010. Al-Qur'an dan Terjemahnya. Surabaya: Pustaka Agung Harapan.

Dewi, S., 2015. Metode Penelitian Dakwah Pendekatan Kualitatif dan Kuantitatif. Bandung: Rosda Karya.

Effendy, O. U., 2004. Ilmu Komunikasi Teori dan Prkatek. Bandung: PT. Remaja 
Rosdakarya.

Effendy, O. U., 1993. Ilmu, Teori dan Filsafat Komunikasi. Bandung: P.T Citra Aditya Bakti

Hartaji, 2012. Motivasi Berprestasi Pada Mahasiswa yang Berkuliah. s.l.:s.n.

Ismail, i. \& Hotman Prio, 2011. Filsafat Dakwah. Jakarta: Kencana

Kamus, T. P. P., 2007. KBBI. s.1.:Balai Pustaka.

Kartini, 1997. s.l.:s.n

KBBI, 2018. [Online]

Available at: https://kbbi.kemdikbud.go.id/

Kusnawan, A., 2004. Komunikasi Penyiaran Islam. Bandung: Benang Merah.

Mar'at, 1982. Sikap Manusia Dan Pengukurannya. Jakarta: Ghalia Indonesia.

Moekijat, 1993. Teori Komunikasi. Bandung: Mandar Maju

Morissan, 2013. Teori Komunikasi. Bogor: Ghalia Indonesia.

Munir, M. \& Wahyu Ilaihi, 2006. Manajemen dakwah. Jakarta: Kencana.

Munir, S., 2009. Ilmu Dakwah. Jakarta: Amzah.

Nisa, N. F, 2018. Retorika K.H. Junaedi Al- Baghdadi dalam pengajian Dzakir

Manaqib dalam Ilmu Dakwah: Academic Journal For Homilete Studies.

Rahmat, J., 2004. Psikologi Komunikasi. Bandung: PT. Remaja Rosda Karya

Rahmat, J., 2008. Psikologi Komunikasi. Bandung: PT. Rosda Karya.

Rahmat, J., 2011. Psikologi Komunikasi. Bandung: Pt Remaja Rosdakarya.

Shaleh, A. R., 1997. Manajemen Dakwah Islam. Jakarta: Bulan Bintang.

Siswoyo, D., 2007. Ilmu Pendidikan. Yogyakarta: s.n.

Supena, I., 2013. Filsafat Ilmu Dakwah. Yogyakarta: Penerbit Ombak.

Suryabrata, S., 1998. Metodologi penelitian. Jakarta: Raja Grafindo Persada.

Wahidin, S., 2012. Pengantar Ilmu Dakwah. Jakarta: Rajawali Pers. 